\title{
Review
}

\section{Analysis of Molecular or Ion Mobility in Glassy and Rubbery Foods by Electric and Proton-NMR Measurements}

\author{
Hitoshi KUMAGAI ${ }^{1 *}$ and Hitomi KUMAGAI ${ }^{2}$ \\ ${ }^{1}$ Department of Applied Biological Chemistry, The University of Tokyo, 1-1-1 Yayoi, Bunkyo-ku, Tokyo 113-8657, Japan \\ ${ }^{2}$ Department of Agricultural and Biological Chemistry, Nihon University, 1866 Kameino, Fujisawa-shi, Kanagawa 252-8510, Japan
}

Received January 15, 2002; Accepted March 26, 2002

\begin{abstract}
The glass transition temperature $T_{\mathrm{g}}$ for many foods has been determined by thermal analysis such as differential scanning calorimetry (DSC). The thermal analysis, however, does not provide information on molecular mobility. In this review, the analysis of the glass transition of foods by electrical methods and proton-NMR was explained and compared with that obtained by DSC. The dielectric relaxation, i.e., the peak of the dielectric loss, $\varepsilon^{\prime \prime}$, was observed for some glassy foods and ascribed to the local motion of molecules. The relaxation time $\tau$ and the activation energy $E_{\text {act }}$ seemed suitable parameters to describe the enhancement effect of water on the mobility of molecules in the glassy state. However, when the ionic conductivity dominated the electrical properties, the $\varepsilon^{\prime \prime}$ peak was masked. For analyzing such a system, the electric modulus, $M^{*}$ was an effective tool. The value of the activation energy obtained through $M^{*}$ formalism in the glassy state was larger than that in the rubbery state, probably due to a change in the free volume size by glass transition. For NMR research, the mobility of glucose syrup in the glassy and rubbery states has been examined. Free induction decay (FID) was measured with low-resolution NMR and was best fitted by a Gaussian lineshape multiplied by sinc function plus an exponential function. The $T_{2}$ of mobile protons reached the rigid-lattice limit at a temperature lower than the midpoint $T_{\mathrm{g}}$ obtained by DSC.
\end{abstract}

Keywords: glass transition, dielectric relaxation, ionic conductivity, electric modulus, proton NMR

\section{Introduction}

We know of many glassy foods, e.g., candy, cookies, pasta, milk powder and so on. When the temperature of a glassy material is increased, the material changes to a rubbery state at the glass transition temperature, $T_{\mathrm{g}}$. The glass transition has attracted great interest among food scientists in recent years, because food materials maintain their physical and chemical stability better in a glassy state than in a rubbery state. It is therefore important to determine $T_{\mathrm{g}}$ to predict food properties and stability. $T_{\mathrm{g}}$ is influenced by food components; in addition, water is known to act as a plasticizer and to depress $T_{\mathrm{g}}$ (Levine $\&$ Slade, 1988). The glass transition temperature $T_{\mathrm{g}}$ for many foods has been determined by thermal analysis such as differential scanning calorimetry (DSC), and the state diagrams ( $T_{\mathrm{g}}$ vs. water content plots) of various food components have been reported (Levine \& Slade, 1993; Orford et al., 1989). Such data have contributed to the prediction of food properties and storage stability (Levine \& Slade, 1993; Borchard et al., 1980).

On a molecular level, a glassy material is considered to be stable because the micro-Brownian motions of the main chains of the polymers are immobilized due to the small free volume. Local segmental motions, however, remain even in a glassy state; polymers in a glassy state approach an equilibrium state over an extended period; the volume, enthalpy, and entropy of a glassy

*Present address: Department of Food Science and Nutrition, Kyoritsu Women's University, 1-710, Motohachioji, Hachioji-shi, Tokyo 193-8501, Japan.

E-mail: hitoshi.kumagai@nifty.ne.jp material consequently decrease, i.e., there is isotropic annealing or physical aging (Johari, 1982; Noel et al., 1993). Information on molecular mobility in the glassy state is therefore also important as well as $T_{\mathrm{g}}$ data. The thermal analysis, however, does not provide information on molecular mobility.

Electrical properties reflect molecular and/or electrolyte (ion) motions in a system, while NMR provides information about the mobility of protons of a molecule in the material. Both techniques are useful tools for evaluating molecular motions in a substance. In this review, the analysis of glass transition of foods by electrical methods and proton-NMR is explained and compared with that obtained by DSC.

2. Determination of the glass transition temperature $T_{\mathrm{g}}$ by DSC (Kumagai et al., 2000; 2002)

The glass transition temperature $T_{\mathrm{g}}$ measured by DSC is primary information, as mentioned. In this review, the DSC data for glucose syrup and gelatin films will be presented as examples. Calorimetric measurements were carried out at a heating rate of $10^{\circ} \mathrm{C} / \mathrm{min}$ using a DSC7 (Perkin Elmer). The midpoint between the onset and end temperatures was taken as $T_{\mathrm{g}}$.

Glassy glucose syrup was prepared by freeze-drying the aqueous solution. Figure 1 (A) shows a typical DSC thermogram of glucose syrup with $0.9 \% \mathrm{k}$-carrageenan. The incremental change in heat flow associated with the glass transition was clearly observed; $T_{\mathrm{g}}$ was evaluated from the midpoints of the DSC curve. Figure 1 (B) shows the dependence of the $T_{\mathrm{g}}$ on water content. The values were almost the same as the literature values 

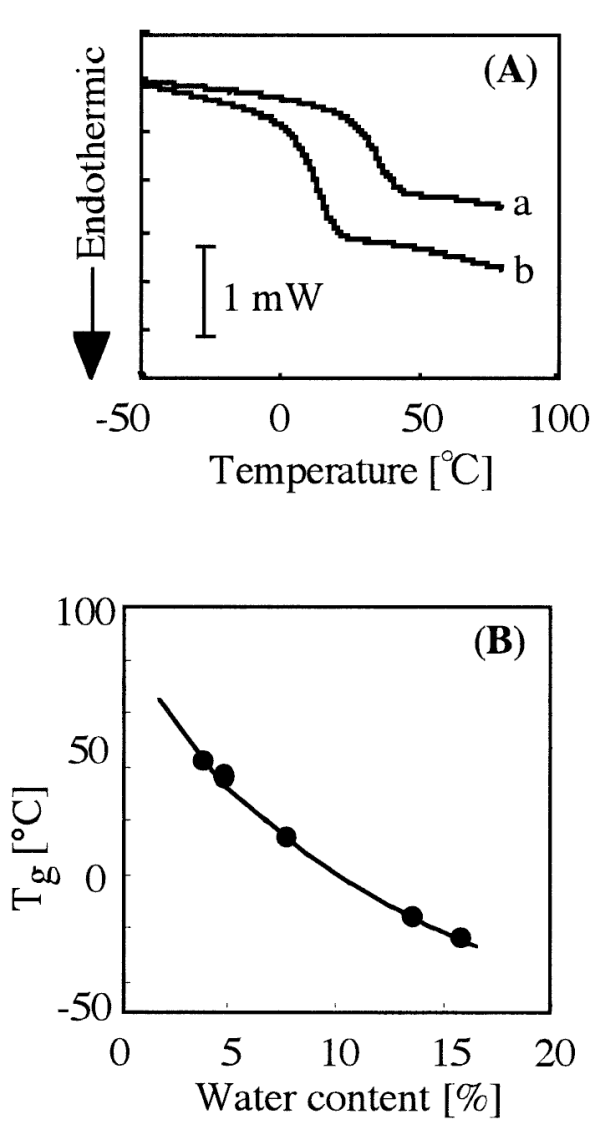

Fig. 1. (A) A typical DSC diagram of glucose syrup with $0.9 \%$ к-carrageenan at a water content of (a) $4.7 \%$ and (b) $8.4 \%$ and (B) the concentration dependence of $T_{\mathrm{g}}$ for glucose syrup. The curve shows literature values of $T_{\mathrm{g}}$ for maltose (Orford et al., 1989).

of $T_{\mathrm{g}}$ for maltose (Orford et al., 1989) because the glucose syrup used had a dextrose equivalent of 42 and thus had properties similar to those of a disaccharide.

A DSC heating curve for a desalted gelatin film is illustrated in Fig. 2. The desalted gelatin films were prepared by "hot-drying" (Marshall \& Petrie, 1980) to prevent the formation of structural order (helix structure or crystallites) as follows: A 10\% (w/ w) aqueous solution was prepared by dissolving the required amount of the desalted gelatin and then heating at $60^{\circ} \mathrm{C}$. The gelatin solution was then kept at $60^{\circ} \mathrm{C}$ for several days. In Fig. 2 (A), $T_{\mathrm{g}}$ is shown by an arrow and was determined to be $145^{\circ} \mathrm{C}$ from the midpoints of the DSC curve. The contour of a DSC diagram of the sample at the second run (the same sample was cooled rapidly in the DSC pan, and the DSC measurement was repeated again) was similar to that in Fig. 2 (A); the value of $T_{\mathrm{g}}$ at the second run agreed well with that shown in Fig. 2. If the specific heat change observed in Fig. 2 (A) is ascribed to a helix-coil transition, the peak for the helix-coil transition would be lost in the second run (Marshall \& Petrie, 1980). Therefore, the specific heat change observed in Fig. 2 (A) is believed to be associated with the glass transition of the gelatin film, not with an endothermic peak for the helix-coil transition.

The water content dependence of $T_{\mathrm{g}}$ for the gelatin film examined is shown in Fig. 2 (B) and is similar to that reported by Levine and Slade (1988). According to their data, the value of $T_{\mathrm{g}}$ increased with decreasing water content for samples with a water content of less than $0.35 \mathrm{~kg} / \mathrm{kg}$ of sample. They concluded, consequently, that an amount of water less than $0.35 \mathrm{~kg} / \mathrm{kg}$ of sample functioned as an effective plasticizer of the amorphous regions of the gelatin polymer. For the gelatin shown in Fig. 2, water is also thought to act as a plasticizer below a water content of $0.12 \mathrm{~kg} /$ $\mathrm{kg}$ of sample.

\section{Dielectric analysis}

\section{1. Dielectric relaxation}

\subsubsection{The electrical properties measured in an alternating current field and dielectric relaxation}

We will now consider the measurement of electrical properties of a material under an alternating current. The dielectric constant, $\varepsilon^{\prime}$, is defined by

$$
\varepsilon^{\prime}=\frac{C}{C_{0}},
$$

where $C$ and $C_{0}$ are the capacitance of the sample and the empty cell, respectively. If a parallel-plate electrode with an area $S$ and a distance $d$ is used for electric measurement, $C$ is related to $\varepsilon^{\prime}$ as follows.

$$
C=\varepsilon^{\prime} e_{0} \frac{S}{d},
$$

where $e_{0}$ is the permittivity in empty space. On the other hand, the conductance of the sample, $G$, is expressed by

$$
G=\sigma^{\prime} \frac{S}{d}
$$
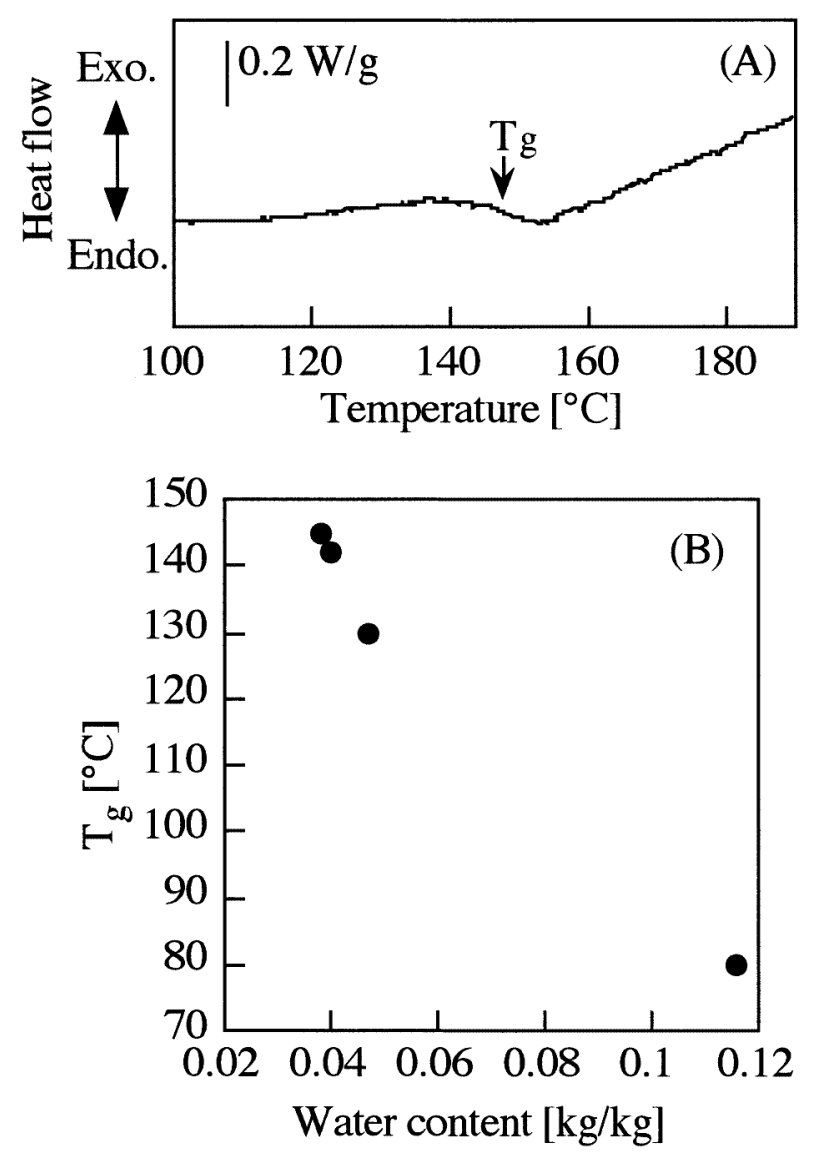

Fig. 2. (A) A typical DSC diagram of a glassy gelatin (water content: $0.0380 \mathrm{~kg} / \mathrm{kg}$ ) and (B) the concentration dependence of $T_{\mathrm{g}}$ for gelatin film. 
where $\sigma^{\prime}$ is the electric conductivity. The dielectric loss, $\varepsilon^{\prime \prime}$, is defined by

$$
\varepsilon^{\prime \prime}=\frac{\sigma^{\prime}}{2 \pi f e_{0}},
$$

where $f$ is the frequency of the alternating current.

In Fig. 3, the behavior of the electrical properties in an alternating current field is conceptually shown. With increasing frequency, the dielectric constant, $\varepsilon^{\prime}$, often decreases due to the delay in dipole moments. At the same time, the electric conductivity $\sigma^{\prime}$ increases and the dielectric loss, $\varepsilon^{\prime \prime}$ shows a peak. This phenomenon is the so-called dielectric relaxation (Maxwell, 1873). From dielectric relaxation data, one can obtain information about the dispersion structure of components in materials such as polyelectrolyte solutions, gels, and the glassy state of food components (Ikeda et al., 1997a, b; Ikeda \& Kumagai, 1997; Iwamoto \& Kumagai, 1998; Ikeda \& Kumagai 1998, Kumagai et al., 2000). From the frequency $f_{\mathrm{m}}$, which gives the maximum of $\varepsilon^{\prime \prime}$, an important parameter, the relaxation time, $\tau$, can be calculated by the following equation.

$$
\tau=\frac{1}{2 \pi f_{m}} \text {. }
$$

Since $\tau$ corresponds to the time needed for the electric dipoles to orient in the direction of an electric field, it can be an index of mobility of electric dipoles (or molecules). If the temperature dependence of $\tau$ is described by the following Arrhenius type equation, the activation energy $E_{\text {act }}$, which corresponds to the energy barrier for the movement of electric dipoles in a system, is calculated from the slope of a semilogarithmic plot of $\tau$ vs. $1 / T$ (Arrhenius plot):

where $R$ is the gas constant.

$$
\tau \propto \exp \left(E_{\text {acl }} / R T\right),
$$

In a glassy state (below $T_{\mathrm{g}}$ ), dielectric relaxation, which arises from the rotation of the side chain of a gelatin molecule and/or the local segmental motion of the backbone chain (McCrum et al., 1967; Boyd, 1985; Dorfmüller \& Williams, 1987; Tatsumi $e t$ al., 1992) is observed; this dielectric relaxation is called $\beta$-(or secondary) relaxation. The values of activation energy $E_{\text {act }}$ are determined to be several decades of $\mathrm{kJ} / \mathrm{mol}$ for synthetic polymers such as polymethyl methacrylate (PMMA) and polyethylene terephthalate (McCrum et al., 1967). Dielectric relaxation has also been observed for concentrated sugar-water systems

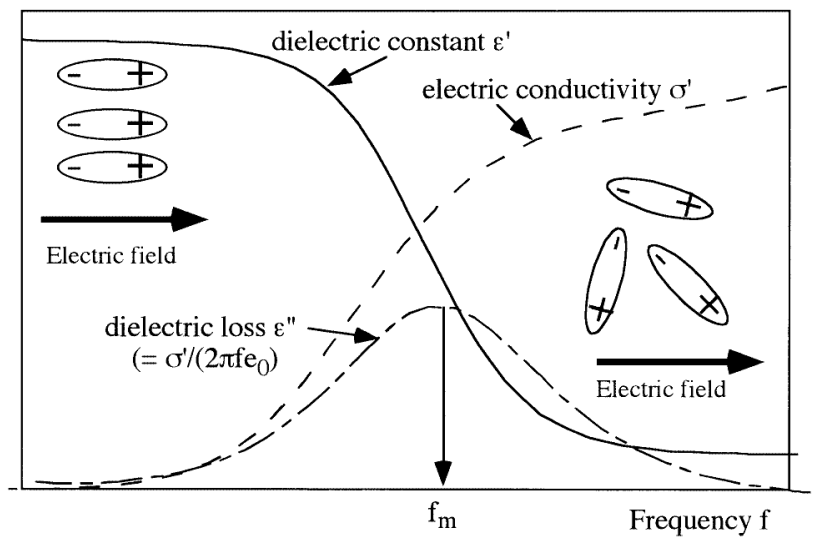

Fig. 3. Electrical properties in alternating current field.
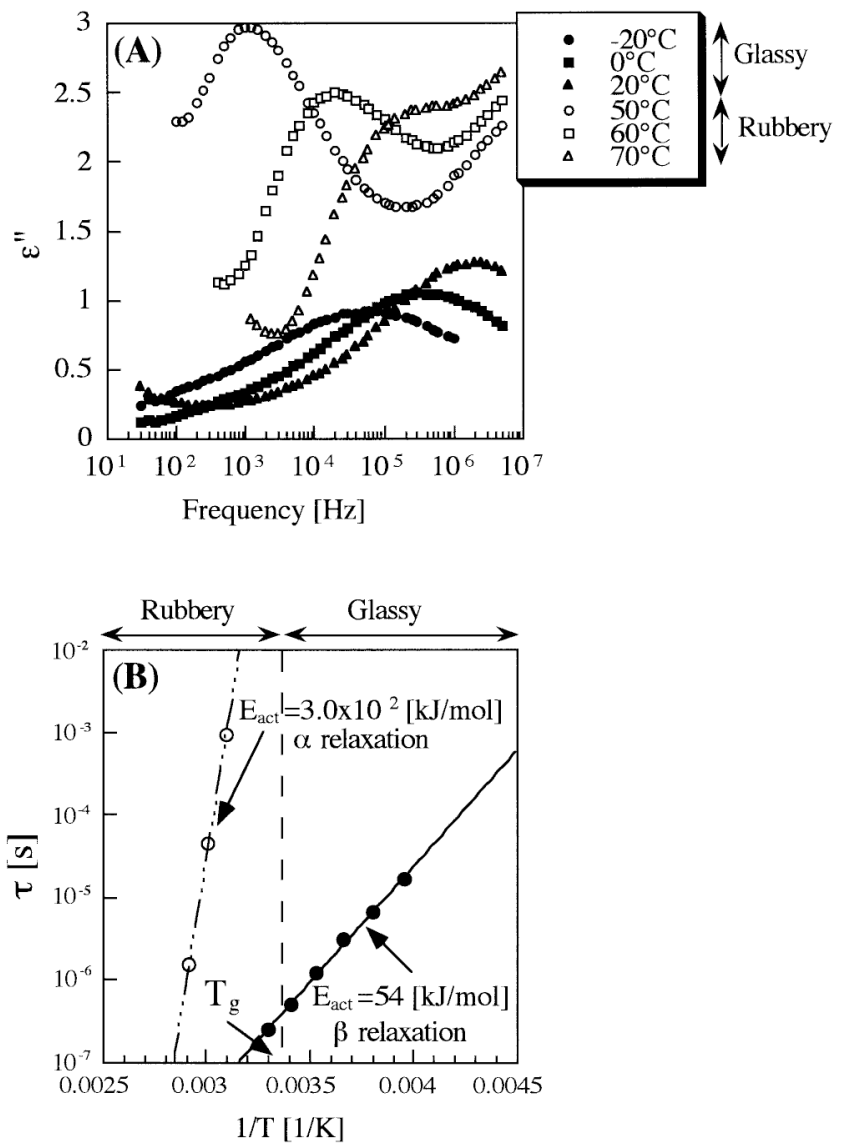

Fig. 4. (A) Frequency dependence of $\varepsilon^{\prime \prime}$ and (B) Arrhenius plot of $\tau$ for maltose. Water content: $0.06 \mathrm{~kg} / \mathrm{kg}$ of sample.

(Nishinari et al., 1985; Scandola et al., 1991; Noel et al., 1992, 1993, 1996; Montes et al., 1997; Murthy et al., 1994). On the other hand, the dielectric relaxation observed in a rubbery state (at temperatures around and above $T_{\mathrm{g}}$ ) is ascribed to the microBrownian motions of the main chains (McCrum et al., 1967; Boyd, 1985). This relaxation is called $\alpha$ - (or the primary) relaxation, and the value of its apparent activation energy $E_{\text {act }}$ is several hundreds $\mathrm{kJ} / \mathrm{mol}$ for synthetic polymers and sugars (Nishinari et al., 1985; Scandola et al., 1991; Noel et al., 1992, 1993, 1996; Montes et al., 1997; Murthy et al., 1994).

3.1.2. The dielectric relaxation of glassy and rubbery foods (Kumagai et al., 2000)

Electrical properties were measured in the frequency range from $100 \mathrm{~Hz}$ to $10^{6} \mathrm{~Hz}$ with LCR meters (Hewlett-Packard Japan, Tokyo, Japan; 4284A and 4285A) equipped with a parallel plate type of cell (Ando Electric Co., Tokyo; SE-70) at the selected temperature.

First, we measured the electrical properties of maltose to determine the characteristics of our equipment. The glassy maltose was prepared by heating maltose at $180^{\circ} \mathrm{C}$ and then quenching it. Figure 4 (A) shows the frequency dependence of dielectric loss $\varepsilon^{\prime \prime}$ for maltose, where the value of $T_{\mathrm{g}}$ was determined to be $25^{\circ} \mathrm{C}$ from DSC measurement. The peaks of $\varepsilon^{\prime \prime}$, i.e., dielectric relaxation, were observed in both the glassy and rubbery states and shifted to higher frequencies with increasing temperature in both states; the relaxation time $\tau$ was therefore calculated by Eq. (5). Figure 4 (B) presents the Arrhenius plots of $\tau$ for maltose in 
the glassy and rubbery states. A linear relationship was observed in these states based on Eq. (6). The values of the activation energy $E_{\text {act }}$ in the rubbery and glassy states were evaluated to be 300 and $54 \mathrm{~kJ} / \mathrm{mol}$, respectively, similar to those reported by Noel et al. (1996). From the orders of the magnitude of $E_{\text {act }}$, the relaxation observed in the rubbery state is believed to be $\alpha$-relaxation and that in the glassy state to be $\beta$-relaxation.

Figure 5 shows a typical dielectric spectra of glassy gelatin. The dielectric relaxation was observed. With increasing temperature, the dielectric loss peaks shifted to higher frequencies; the enhancement of local molecular mobility can be estimated.

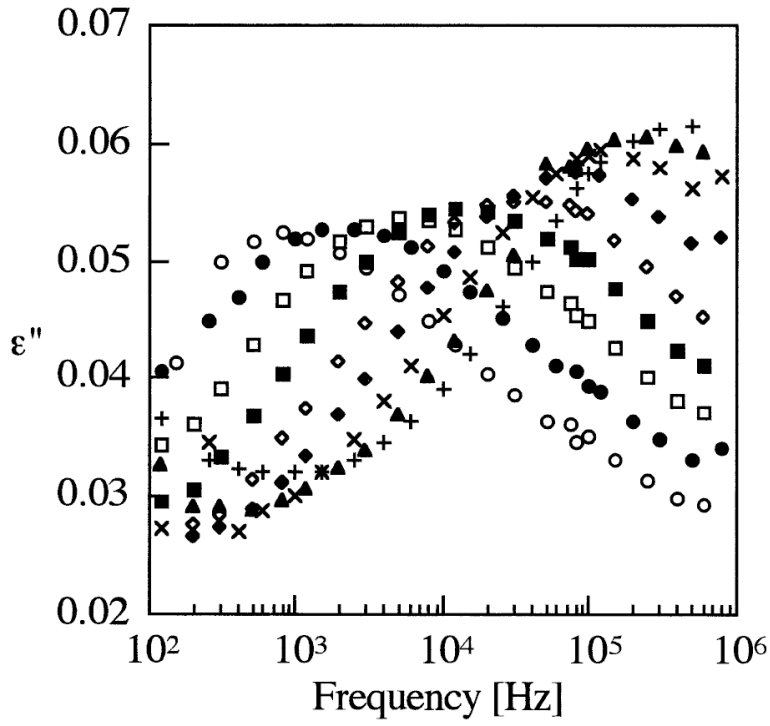

Fig. 5. Frequency dependence of dielectric loss $\varepsilon^{\prime \prime}$ for a glassy desalted gelatin film.

Water content: $0.0380 \mathrm{~kg} / \mathrm{kg}$ of sample, $T_{\mathrm{g}}: 145^{\circ} \mathrm{C}$. Temperature: $\circ ;-20^{\circ} \mathrm{C}$, $\bullet ;-10^{\circ} \mathrm{C}, \square ; 00^{\circ} \mathrm{C},-10^{\circ} \mathrm{C}, \diamond ; 20^{\circ} \mathrm{C}, \diamond ; 30^{\circ} \mathrm{C}, \times ; 40^{\circ} \mathrm{C}, \mathbf{\Delta} ; 50^{\circ} \mathrm{C},+; 60^{\circ} \mathrm{C}$

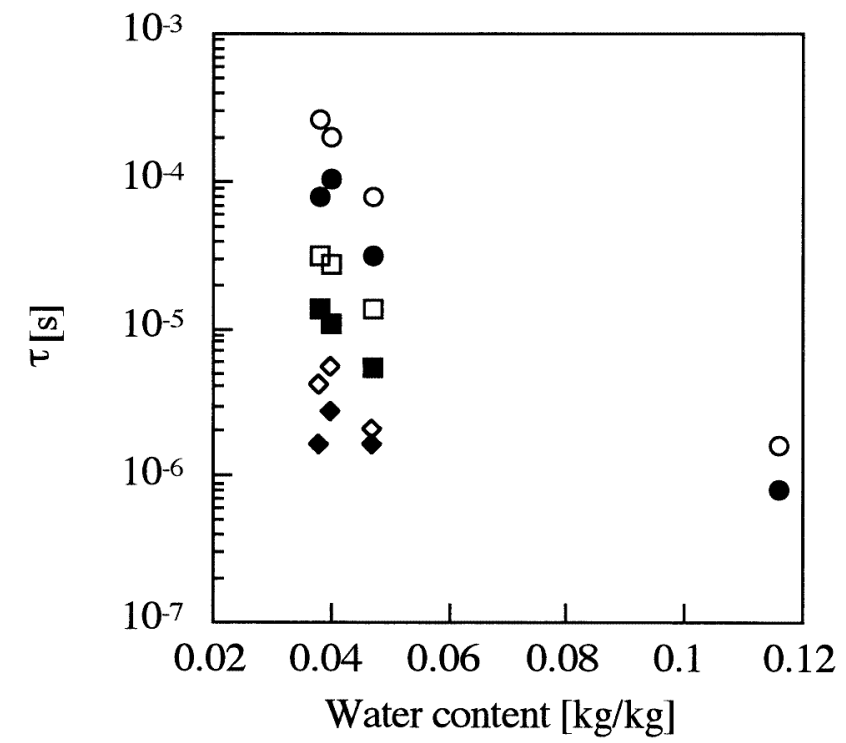

Fig. 6. The dependence of the relaxation time $\tau$ on water content of glassy gelatin.

Temperature: $\circ ;-20^{\circ} \mathrm{C}, \bullet ;-10^{\circ} \mathrm{C}, \square ; 0^{\circ} \mathrm{C}, \mathbf{\square} ; 10^{\circ} \mathrm{C}, \diamond ; 20^{\circ} \mathrm{C}, \bullet ; 30^{\circ} \mathrm{C}, \times$; $40^{\circ} \mathrm{C}, \Delta ; 50^{\circ} \mathrm{C},+; 60^{\circ} \mathrm{C}$.
The dependence of the relaxation time $\tau$ on water content for a gelatin film is shown in Fig. 6. From the $T_{\mathrm{g}}$ data in Fig. 2 (B), the samples were confirmed to be in a glassy state in this temperature region. The value of $\tau$ was larger for lower temperature at an identical water content and decreased sharply as water content increased. The relaxation time $\tau$ can be the time needed for the electric dipoles to orient in the direction of the electric field and increases as the local viscosity increases (Noel et al., 1993). A temperature increase would cause the local viscosity to decrease, resulting in a decrease in $\tau$. Moreover, as shown in Fig. 6, the value of $\tau$ decreased sharply with increasing water content. Water is the most important plasticizer for food, and, as described before, is also considered to act as a plasticizer for gelatin in the region of water content below $0.12 \mathrm{~kg} / \mathrm{kg}$ of sample (see Fig. 2 (B)). Plasticization, on a molecular level, leads to increased intermolecular space or free volume and decreased local viscosity (Levine \& Slade, 1993). Local viscosity would be decreased by
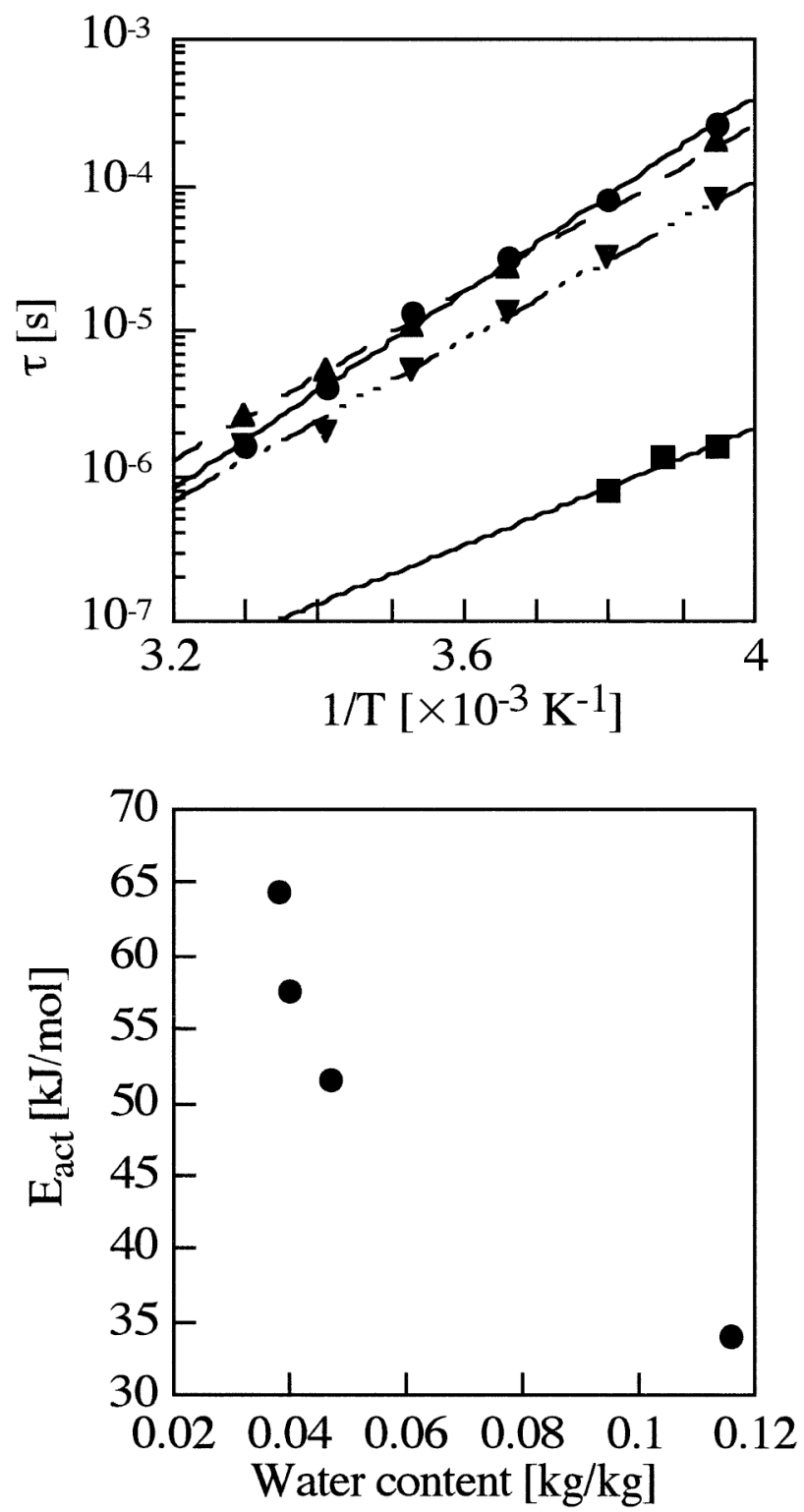

Fig. 7. (A) Arrhenius plots of $\tau$ for a gelatin-water system and (B) dependence of the activation energy $E_{\text {act }}$ on water content.

Water content $[\mathrm{kg} / \mathrm{kg}$ of sample]: $\mathbf{\square} ; 0.116, \mathbf{v} ; 0.0470, \mathbf{\Delta} ; 0.0400, \bullet ; 0.0380$. 
the plasticizing effect of water, causing a reduction in the value of $\tau$, as shown in Fig. 6. The relaxation time $\tau$ seems to describe the enhancement effect of water on the mobility of gelatin molecules in the glassy state. Of course, the relaxation time $\tau$ reflects the movement of electric dipoles in the electric field. However, a difference in the mobility of molecular chains between materials could be relatively compared.

Figure 7 (A) presents the Arrhenius plots of $\tau$ for glassy gelatin films. For all the samples, a linear relationship was observed, and the activation energies $E_{\text {act }}$ were obtained from Eq. (6). Figure 7 (B) shows the dependence of activation energy $E_{\text {act }}$ on water content. Based on the order of the magnitude of $E_{\text {act }}$, the dielectric relaxations observed for the samples examined were considered to reflect the local motion of the main chain or motion of the side chain of the polymer (McCrum et al., 1967; Boyd, 1985; Dorfmüller \& Williams, 1987). The value of $E_{\text {act }}$ decreased from $64.5 \mathrm{~kJ} / \mathrm{mol}$ to $34.0 \mathrm{~kJ} / \mathrm{mol}$ with increasing water contents from 0.0380 to $0.116 \mathrm{~kg} / \mathrm{kg}$ of sample. The activation energy $E_{\text {act }}$ is the energy barrier for the movement of electric dipoles in a system (McCrum et al., 1967). Water would have decreased the local viscosity of the gelatin films and reduced the value of $E_{\text {act }}$. Both $\tau$ and $E_{\text {act }}$ can describe the enhancement effect of water on the mobility of gelatin molecules in the glassy state. The relaxation time $\tau$ is influenced not only by water content but also by temperature, as shown in Fig. 6. On the other hand, $E_{\text {act }}$ takes an intrinsic value for a sample at a selected water content; in addition, the relaxation type ( $\alpha$ or $\beta$ ) can be discriminated from the order of the magnitude of $E_{\text {act }}$.

The values of activation energy $E_{\text {act }}$ evaluated in this study are summarized in Table 1. For polyethylene terephthalate (PET) and maltose, dielectric relaxation was observed both in the glassy and the rubbery state. However, for dextran, gelatin, and gluten, dielectric relaxation was observed in the glassy state only, and the dielectric loss peak was masked in the rubbery state, probably due to the large dc conductivity (low-frequency limit of electric conductivity). In the following part of this review, the method for analyzing such materials in the glassy and rubbery states will be explained.

3.2. The complex dielectric permittivity and analysis of ion mobility by the electric modulus.

At low frequencies and at relatively high temperatures around or above $T_{\mathrm{g}}$, the peak of $\varepsilon^{\prime \prime}$ for materials containing electrolytes and/or water is often masked due to the large dc conductivity, $\sigma_{0}$, caused by electrolytes; this ionic conduction makes it difficult to measure the dielectric relaxation for polymer-water systems. In these cases, an electric modulus $M^{*}$, which has been applied to

Table 1. The values of activation energy $E_{\text {act }}$.

\begin{tabular}{lcrlc}
\hline Sample & $\begin{array}{c}\text { Concentration } \\
{[\mathrm{kg} / \mathrm{kg}]}\end{array}$ & $T_{\mathrm{g}}\left[{ }^{\circ} \mathrm{C}\right]$ & State & $\begin{array}{c}\text { Activation energy } E_{\text {act }} \\
{[\mathrm{kJ} / \mathrm{mol}]}\end{array}$ \\
\hline \multirow{2}{*}{ PET } & - & 78 & $\begin{array}{l}\text { rubbery } \\
\text { glassy }\end{array}$ & $\begin{array}{c}620 \\
57\end{array}$ \\
\hline \multirow{2}{*}{ Maltose } & 0.94 & 25 & $\begin{array}{l}\text { rubbery } \\
\text { glassy }\end{array}$ & $\begin{array}{c}300 \\
\text { Dextran }\end{array}$ \\
\hline \multirow{2}{*}{ Geratin } & 0.97 & 180 & glassy & 76 \\
\hline Gluten & 0.884 & 80 & glassy & 34.0 \\
\hline
\end{tabular}

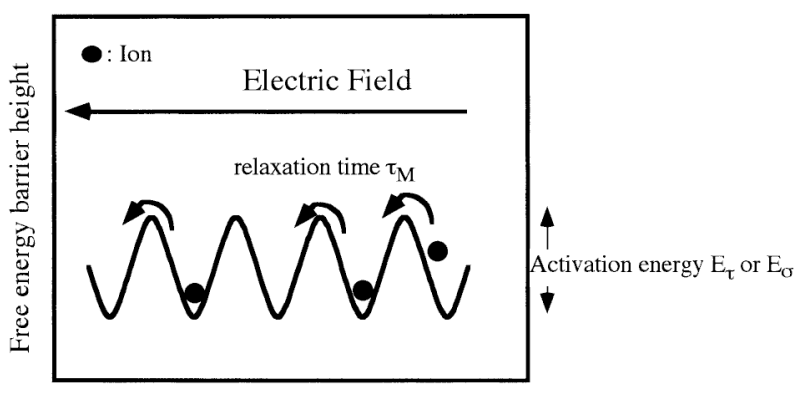

Fig. 8. Physical meaning of the parameters in ionic conduction model.

ionic glasses, is often effective (Ambrus et al., 1972; Higgins et al.,1972; Macedo et al.,1972; Provenzano et al., 1972; Moynihan et al., 1973; McLin \& Angell, 1988; Angell, 1990; Jain \& Johari, 1990; Cole \& Tombari, 1991; Cole, 1991; Moynihan, 1994; Nowick \& Lim, 1994; Pathmanathan \& Johari, 1994; Moynihan, 1996; Munro et al., 1996; Wagner \& Richert, 1997). In this part, the analysis of glassy and rubbery materials by the electric modulus will be described.

3.2.1. The complex dielectric permittivity and the electric modulus

The complex dielectric permittivity $\varepsilon^{*}$ is defined by

$$
\varepsilon^{*}=\varepsilon^{\prime}-i \varepsilon^{\prime \prime}
$$

where $i$ is an imaginary unit. The electric modulus $M^{*}$ is defined as the reciprocal of $\varepsilon^{*}$; the real part, $M^{\prime}$, and the imaginary part, $M^{\prime \prime}$, of $M^{*}$ are expressed as follows.

$$
\begin{aligned}
M^{\prime} & =\frac{\varepsilon^{\prime}}{\varepsilon^{2}+\varepsilon^{\prime 2}}, \\
M^{\prime \prime} & =\frac{\varepsilon^{\prime \prime}}{\varepsilon^{\prime 2}+\varepsilon^{\prime 2}} .
\end{aligned}
$$

A peak in the $M^{\prime \prime}$ vs. $f$ plot is observed; this phenomenon is called the electrical relaxation (Ambrus et al., 1972; Macedo et al., 1972; Moynihan et al., 1973). In this study, only the imaginary part, $M^{\prime \prime}$, is used for the analysis.

The relaxation time, $\tau_{\mathrm{M}}$, is calculated approximately from the peak top frequency, $f_{\mathrm{M}}$, of an $M^{\prime \prime}$ spectra ( $M^{\prime \prime}$ vs. $f$ plot) by the following equation:

$$
\tau_{\mathrm{M}}=\frac{1}{2 \pi f_{\mathrm{M}}} .
$$

This relation is valid for symmetrical relaxation. If the relaxation diagrams of glassy polymers are not symmetrical, it is better to evaluate $\tau_{M}$ by fitting the $M^{\prime \prime}$ data to the Havriliak-Negami type equation (Havriliak \& Negami, 1966; Moynihan, 1996).

If the temperature dependence of $\tau_{M}$ is described by the following Arrhenius type equation, the activation energy, $E_{\tau}$, is calculated from the slope of the semilogarithmic plot of $1 / \tau_{\mathrm{M}}$ vs. $1 / T$ (Arrhenius plot):

$$
1 / \tau_{\mathrm{M}} \propto \exp \left(-E_{\tau} / R T\right)
$$

If the dc conductivity $\sigma_{0}$ is not negligible, the equivalent value of $\sigma_{0}$ is evaluated by the extrapolation to zero frequency of the circular arc locus for complex resistivity, $\rho^{*}$ (Cole, 1991; Cole \& Tombari, 1991). If the temperature dependence of $\sigma_{0}$ shows Arrhenius type behavior, the activation energy, $E_{\sigma}$, is calculated by the following equation. 


$$
\sigma_{0} \propto \exp \left(-\frac{E_{\sigma}}{R T}\right)
$$

If the value of $E_{\sigma}$ agrees with that of $E_{\tau}$, the observed electrical relaxation can be ascribed to ionic conduction. In this case, the relaxation time $\tau_{M}$ can be the time needed for the ions to move from one lattice site to another in a polymeric solid during the conduction process and the activation energy $\left(E_{\sigma}\right.$ or $\left.E_{\tau}\right)$ is the energy barrier for the ion movement (Macedo et al., 1972), as illustrated in Fig. 8.

If the observed electrical relaxation is ascribed to an electric dipole orientation, the value of $E_{\tau}$ is similar to that of $E_{\text {act }}$. In this case, the peak of $M^{\prime \prime}$ is observed in the frequency region near that of $\varepsilon^{\prime \prime}$; the value of $\tau_{M}$ is known to be slightly smaller than that of $\tau$ (Ambrus et al., 1972).

3.2.2. Analysis of glassy and rubbery gelatin films by the electric modulus (Iwamoto et al., 1999)

A $60 \%(\mathrm{w} / \mathrm{w})$ aqueous solution was prepared by dissolving the required amount of the desalted gelatin and then heating at $90^{\circ} \mathrm{C}$ overnight. The sample was cooled rapidly in liquid nitrogen and then dried under vacuum. By varying the drying time, three samples with different gelatin concentration were obtained; hereafter in this section, the samples are referred to as Samples A, B, and C. The gelatin concentrations of Samples A, B, and C were determined to be $0.665,0.830$, and $0.863 \mathrm{~kg} / \mathrm{kg}$, respectively, based on the decrease in weight on drying under vacuum at $60^{\circ} \mathrm{C}$ with $\mathrm{P}_{2} \mathrm{O}_{5}$.

Typical isothermal spectra of $\varepsilon^{\prime}$ and $\varepsilon^{\prime \prime}$ for a gelatin film at $30^{\circ} \mathrm{C}$ are shown in Fig. 9 (A). The value of $\varepsilon^{\prime}$ increases rapidly with decreasing frequency, and the $\varepsilon^{\prime \prime}$ spectra show no peaks. The loss $\varepsilon^{\prime \prime}$ is considered to be masked because of the large dc conductivity. The $\varepsilon^{*}$ data were therefore transformed into $M^{*}$ formalism to resolve whether a dipolar relaxation process contributes to the $\varepsilon^{\prime}$ and $\varepsilon^{\prime \prime}$. In Fig. 9 (B), the frequency dependences of $M^{\prime}$ and $M^{\prime \prime}$ for the same gelatin film as that in Fig. 9 (A) are shown; a peak of $M^{\prime \prime}$, i.e., the electrical relaxation, was observed.

The frequency dependences of $M^{\prime \prime}$ for gelatin films at various temperatures are shown in Fig. 10. In the temperature range of 0 to $50^{\circ} \mathrm{C}$, Sample $\mathrm{A}$ is in the rubbery state and Sample $\mathrm{C}$ is in the glassy state. Sample B changes from the glassy to the rubbery state at $45^{\circ} \mathrm{C}$ as the temperature is increased. At an identical temperature, $M^{\prime \prime}$ showed a peak at higher frequency for the lower concentration sample. As shown later (in Fig. 11 (A)), these results mean that the value of the relaxation time $\tau_{M}$ is larger for the glassy sample (lower concentration and temperature) than that for the rubbery sample (higher concentration and temperature).

Figure 11 (A) shows Arrhenius plots of $1 / \tau_{M}$ for Samples A, B, and C. For Samples A and C, a linear relationship was observed and the activation energies $E_{\tau}$ can be calculated by Eq. (11). For Sample B, the plot was not linear, probably because this sample was in a glassy state below $45^{\circ} \mathrm{C}$ and in a rubbery state above $45^{\circ} \mathrm{C}$. Figure 11 (B) shows Arrhenius plots of $\sigma_{0}$ for Samples A, B, and C. For Samples A and C, a linear relationship was observed and the activation energies $E_{\sigma}$ were calculated by Eq. (12). For Sample B, the plot was not linear, similar to that in Fig. 11 (A).

In Table 2, the values of $E_{\tau}$ and $E_{\sigma}$ for Samples $\mathrm{A}$ and $\mathrm{C}$ are listed. The value of $E_{\tau}$ was close to that of $E_{\sigma}$ for each sample, indicating that the electrical relaxation observed in Fig. 10 can be ascribed to ionic conduction. The value of the activation energy for the glassy gelatin (Sample C) was larger than that for the rubbery one (Sample A).

If the electrical relaxation arises from ionic conduction, $\tau_{\mathrm{M}}$ can be the time needed for the ions to move from one site to another during the conduction process; $E_{\tau}$ (or $E_{\sigma}$ ) corresponds to the energy barrier for their movement, as explained in Fig. 8. As can be seen from Fig. 11, $\tau_{\mathrm{M}}$ values of the glassy material were larger than that of the rubbery one at an identical temperature. In addition, the value of $E_{\tau}$ (or $E_{\sigma}$ ) in the glassy state was larger than that in the rubbery state, as shown in Table 2. It has also been observed in polymer electrolytes (Binks \& Sharples, 1968; Bannister et al., 1984) that the value of the activation energy for ionic conduction is smaller in the rubbery state than that in the glassy state. The ionic mobilities should be subject to the mobility of the polymer backbone as reflected in the activation energy for con-
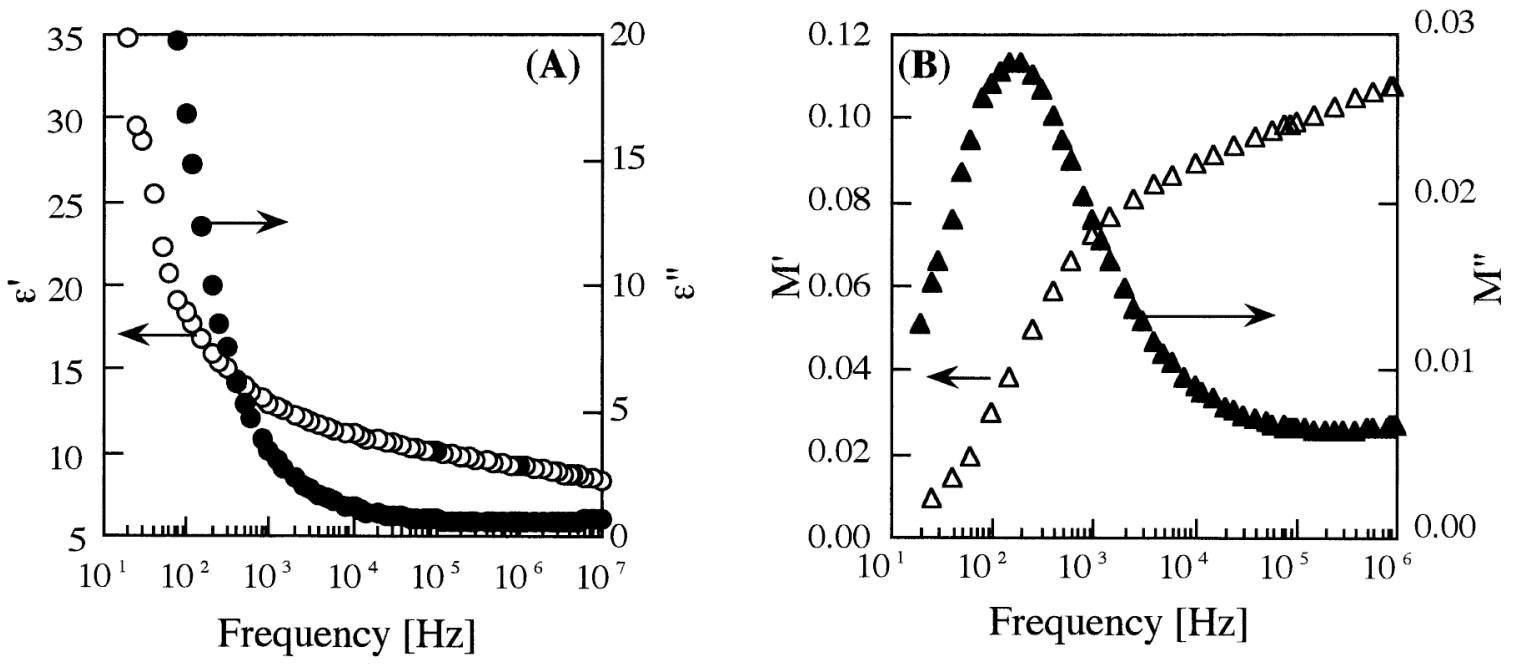

Fig. 9. Frequency dependence of electrical properties for gelatin-water system.

(A) Dielectric constant $\varepsilon^{\prime}$ and dielectric loss $\varepsilon^{\prime \prime}$. (B) Real and imaginary parts of electric modulus $M^{*}$. Gelatin concentration: $0.854 \mathrm{~kg} / \mathrm{kg}$, Temperature: $30^{\circ} \mathrm{C}$. 
duction (Angell, 1966; Binks \& Sharples, 1968; Bannister et al., 1984). It is popular in polymer science to associate this behavior of $\tau_{\mathrm{M}}$ and $E_{\tau}$ with an increase in "free volume" that accompanies a temperature increase, a "critical" fluctuation in local free volume being assumed to be the necessary condition for ion diffusive motion to occur (Angell, 1966; Bannister et al., 1984).

\subsection{Conclusions on dielectric analysis of glass transition}

(1) The dielectric relaxation, which is the peak of the dielectric loss $\varepsilon^{\prime \prime}$, was observed for some glassy food materials. From the orders of magnitude of the activation energy $E_{\text {act }}$, the relaxations observed in the glassy state were believed to reflect the local motion of the main chain or motion of the side chain of the polymer.

(2) The relaxation time $\tau$ and the activation energy $E_{\text {act }}$ seemed suitable parameters to describe the enhancement

(A) Rubbery

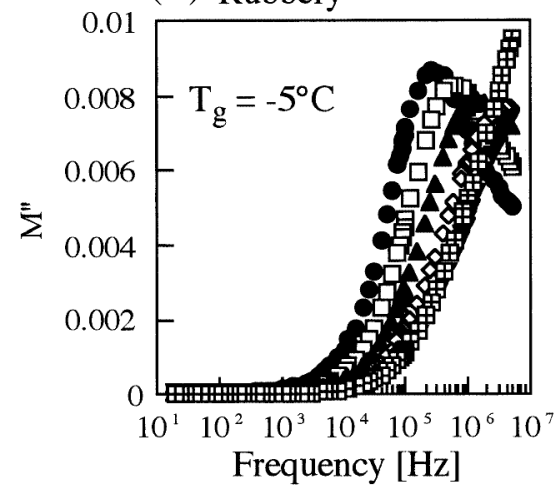

(B) Glassy and Rubbery
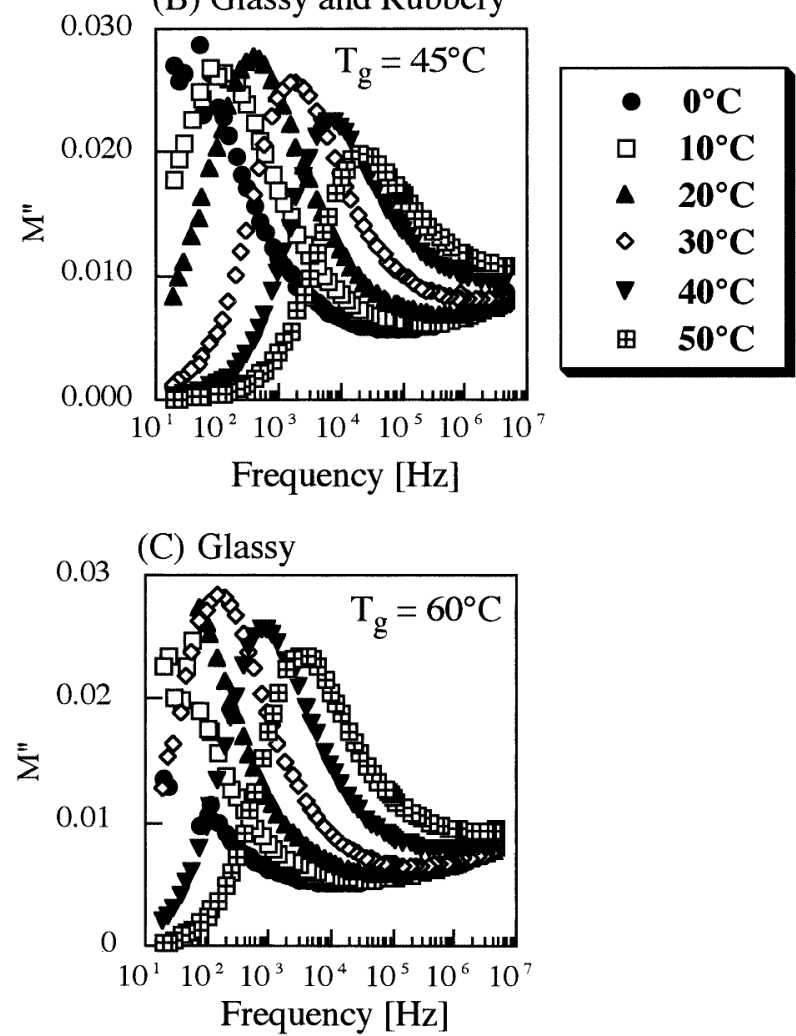

Fig. 10. Frequency dependence of imaginary part of electric modulus $M^{\prime \prime}$ for gelatin-water systems.

Gelatin concentration: (A) $0.665 \mathrm{~kg} / \mathrm{kg}$, (B) $0.830 \mathrm{~kg} / \mathrm{kg}$, (C) $0.863 \mathrm{~kg} / \mathrm{kg}$. effect of water on the mobility of gelatin molecules in the glassy state.

However, when the ionic conductivity dominated the electric properties, the $\varepsilon^{\prime \prime}$ peak was masked and the dielectric measurement was difficult. For analyzing such a system, the electric modulus was effective.

(3) The peak of electric modulus $M^{\prime \prime}$, i.e., the electrical relaxation, was observed both in the glassy and rubbery states even if the loss peak was masked.

(4) The relaxation of $M^{\prime \prime}$ observed for the gelatin was considered ascribable to ionic conduction because the values of $E_{\tau}$ were similar to those of $E_{\sigma}$.

(5) The value of the activation energy $E_{\tau}\left(\right.$ or $\left.E_{\sigma}\right)$ in the glassy state was larger than that in the rubbery state, probably because the change in free volume size due to the glass transition.
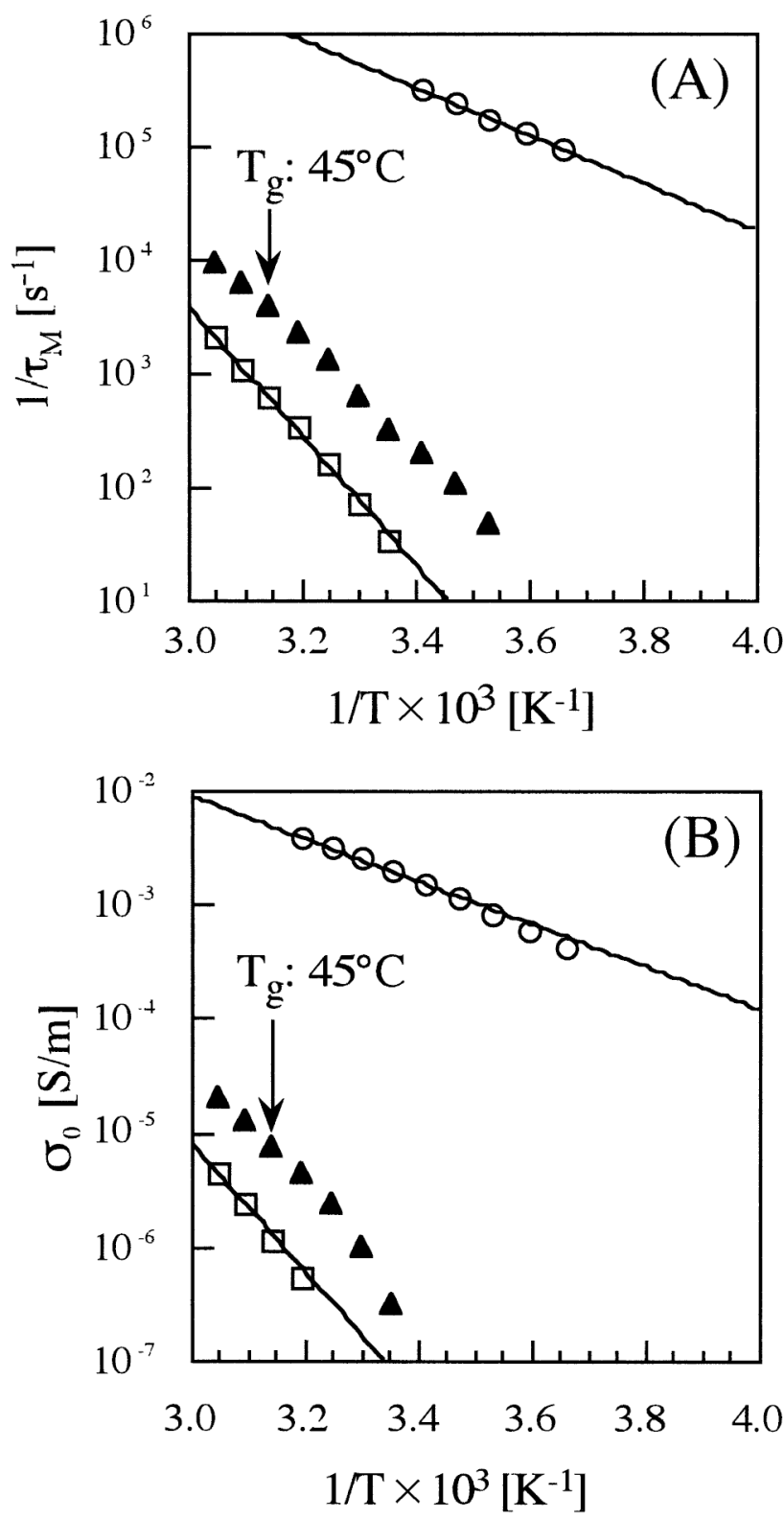

Fig. 11. Arrhenius plots of (A) $1 / \tau_{M}$ and (B) $\sigma_{0}$ for gelatin films. Gelatin concentration: $\bigcirc ; 0.665 \mathrm{~kg} / \mathrm{kg}$ (Sample A), $\mathbf{\Delta} ; 0.830 \mathrm{~kg} / \mathrm{kg}$ (Sample B), $\square ; 0.863 \mathrm{~kg} / \mathrm{kg}$ (Sample C). 
Table 2. The values of activation energies obtained by analysis using the electric modulus.

\begin{tabular}{lclcc}
\hline Sample & Gelatin Conc. $[\mathrm{kg} / \mathrm{kg}]$ & State & $E_{\tau}[\mathrm{kJ} / \mathrm{mol}]$ & $E_{\sigma}[\mathrm{kJ} / \mathrm{mol}]$ \\
\hline A & 0.665 & Rubbery & 40.3 & 40.5 \\
C & 0.863 & Glassy & 110 & 111 \\
\hline
\end{tabular}

\section{Analysis of molecular mobility in glassy and rubbery foods by proton NMR}

\subsection{NMR measurement and the analysis of FID}

NMR is a spectroscopic technique that can detect the mobility of the components in the system by analyzing the relaxation behavior of the protons. The spin-spin relaxation time $T_{2}$ is directly related to molecular mobility over a wide range of the correlation time (Ablett et al., 1993). Van den Dries et al. (1998) used the second moment $M_{2}$ to obtain information on the mobility of the immobile protons and the spin-spin relaxation time $T_{2}$ to obtain that of the mobile protons by utilizing a two-component system. We analyzed the free induction decay (FID) utilizing a three-component system and obtained $M_{2}$ for the mobility of the immobile protons and $T_{2}$ for that of mobile protons, respectively.

FID was measured with ${ }^{1} \mathrm{H}$ NMR equipment (Resonance Instruments MARAN23) at a resonance frequency of $23 \mathrm{MHz}$ equipped with temperature control. The temperature range used for the FID measurement was from $-35^{\circ} \mathrm{C}$ to $55^{\circ} \mathrm{C}$ and the duration of $90^{\circ}$ pulse was $2-3 \mu \mathrm{s}$. Samples were sealed in NMR tubes of $8 \mathrm{~mm}$ I.D., and the FID was measured after equilibration at each temperature.

The NMR signal was fitted to the following equation:

$$
S(t)=A_{1} \exp \left(\frac{-a^{2} t^{2}}{2}\right) \frac{\sin b t}{b t}+A_{2} \exp \left(\frac{-t}{T_{22}}\right)+A_{3} \exp \left(\frac{-t^{2}}{T_{23}^{2}}\right),
$$

where $A_{i}$ is the amplitude of component $i, T_{2 i}$ is the spin-spin relaxation time of the mobile component $i, b$ is the half-width of an immobile proton spectrum (assumed to be rectangular), and $a$ is the standard deviation of the Gaussian lineshape which is con-

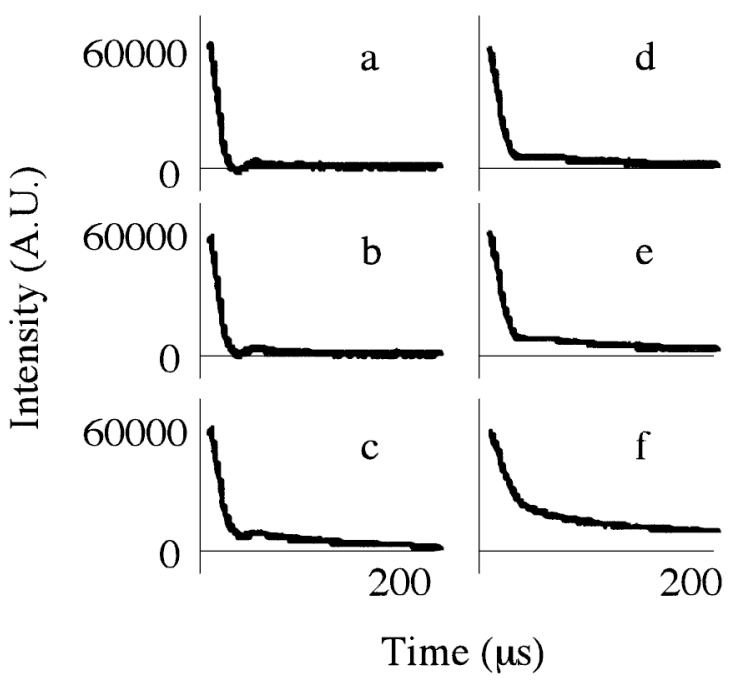

Fig. 12. Free induction decays of glucose syrup with $0.9 \%$ k-carrageenan at different water contents at $25^{\circ} \mathrm{C}(\mathrm{a}, \mathrm{b}, \mathrm{c})$ and $55^{\circ} \mathrm{C}(\mathrm{d}, \mathrm{e}, \mathrm{f})$. water content: $3.5 \%$ (a, d), $4.7 \%$ (b, e), $8.4 \%$ (c, f).

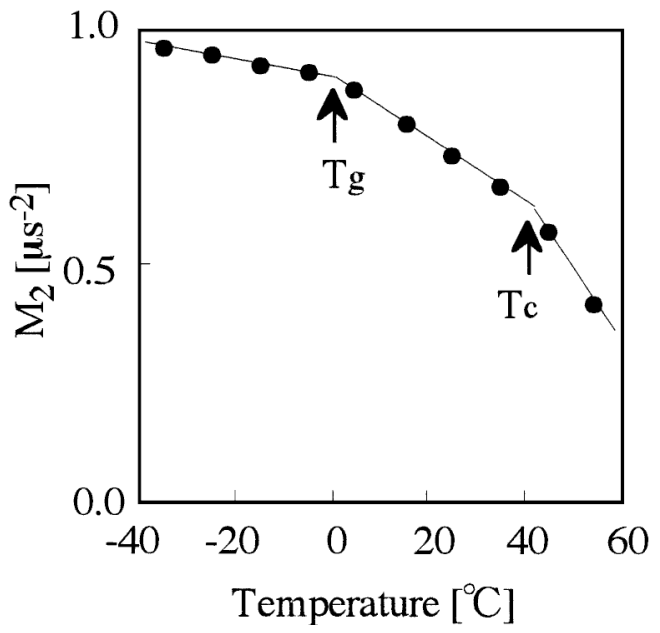

Fig. 13. The second moment of the immobile component (component 1 in Eq. (13)) of glucose syrup with $0.9 \% \mathrm{\kappa}$-carrageenan and $0.14 \% \mathrm{KCl}$ at $8.4 \%$ water content.

voluted with the immobile proton spectrum (McBrierty \& Packer, 1995; Van den Dries et al., 1998). Component 3 was obtained only under conditions of high temperature and/or high water content, typically well into the rubbery state.

In order to monitor the mobility of the immobile protons, the second moment was calculated (Van den Dries et al., 1998; Buitink et al., 2000):

$$
M_{2}=a^{2}+\frac{b^{2}}{3} .
$$

The second moment $\left(M_{2}\right)$ represents the mobility of the immobile component (component 1), while $T_{22}$ and $T_{23}$ represent that of the relatively mobile component (component 2 ) and the additional mobile component (component 3), respectively. These values are obtained by fitting the FIDs with Eq. (13).

4.2. Analysis of molecular mobility in sugars in the glass and rubbery states by NMR (Kumagai et al., 2002)

Figure 12 shows typical free induction decays of glucose syrup with $0.9 \%$ k-carrageenan at $25^{\circ} \mathrm{C}$ and $55^{\circ} \mathrm{C}$. At the lower temperature and the lower water content, the FID had a sinc pattern characteristic of low molecular mobility and strong dipolar interaction in the solid component. As the temperature and/or water content increased, the sinc pattern became less pronounced and disappeared under conditions where the material was well into the rubbery state. All the FIDs were successfully described by Eq. (13). A biexponential lineshape was suggested for the NMR signal of mobile systems, i.e., in the rubbery state, by Hills and Pardoe (1995). However, for the data obtained here, fitting based on Eq. (13) gave a more satisfactory description. The value of $b$ became smaller and the sinc part approached unity as the sinc pattern became less pronounced. An additional mobile component (component 3), with a gaussian lineshape was then obtained.

Figure 13 shows the $M_{2}$ of glucose syrup with $0.9 \%$ k-carrageenan and $0.14 \% \mathrm{KCl}$ at $8.4 \%$ water content. As the temperature increased, $M_{2}$ decreased. The dependency of $M_{2}$ on temperature showed typically one or two transition temperatures where the $M_{2}$ decrease became steeper, reflecting motional changes in the 
immobile component. The lower of these 2 transitions was assigned by Hemminga and co-workers (Buitink et al., 2000) to the onset of significant molecular mobility associated with the glass transition temperature $\left(T_{\mathrm{g}}\right)$. The second transition temperature referred to as the critical temperature $\left(T_{c}\right)$ was associated with the crossover from solid-like to liquid-like dynamics where the material first begins to show properties of a viscous liquid (Rössler et al., 1994).

Figure 14 shows the spin-spin relaxation time $\left(T_{2}\right)$ of glucose syrup with $0.9 \%$ к-carrageenan and $0.14 \% \mathrm{KCl}$ at $8.4 \%$ water content. The $T_{2}$ of the component $2\left(T_{22}\right)$ showed a clear onset of mobility. Hills and Pardoe (1995) reported that a $10 \%$ maltose solution showed a dramatic change in $T_{2}$ at ca. $280-285 \mathrm{~K}$, though they did not compare this discontinuity temperature obtained by NMR with $T_{\mathrm{g}} \mathrm{s}$ measured using other techniques. Ablett et al. (1992) demonstrated increases in $T_{2}$ with low resolution NMR in approximately the correct temperature range as the

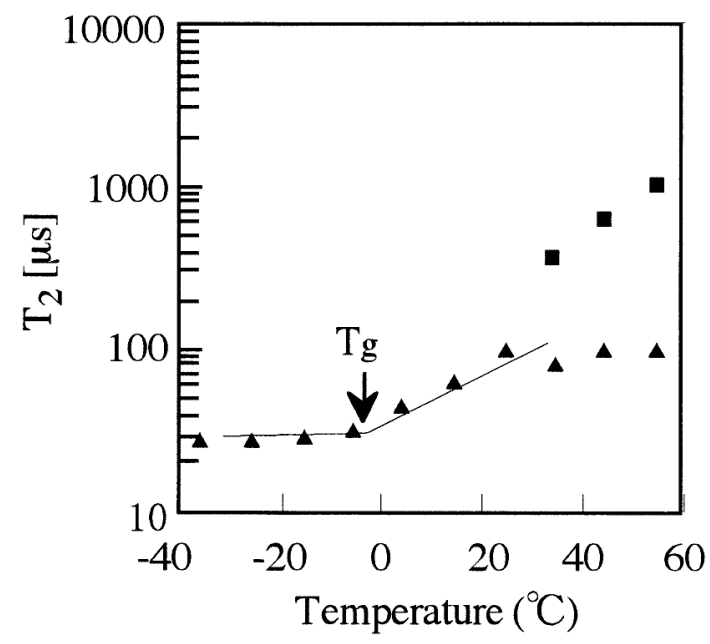

Fig. 14. The spin-spin relaxation time of the mobile components of glucose syrup with $0.9 \% \mathrm{\kappa}$-carrageenan and $0.14 \% \mathrm{KCl}$ at $8.4 \%$ water content. $\mathbf{\Delta}$; component 2, $\mathbf{a}$; component 3 in Eq. (13).
$T_{\mathrm{g}}$ measured by DSC. Kalichevsky et al. (1992) compared the $T_{\mathrm{g}}$ of amylopectin using different techniques. They reported that $T_{\mathrm{g}}$ obtained by NMR was $20-30^{\circ} \mathrm{C}$ lower than that measured by DSC while $T_{\mathrm{g}}$ obtained by DMTA was $10-20^{\circ} \mathrm{C}$ higher than $T_{\mathrm{g}}$ measured by DSC. The inflection point obtained with our sample by NMR was about $10^{\circ} \mathrm{C}$ lower than the DSC $T_{\mathrm{g}}$ midpoint. The reason for this discrepancy is unclear, but DSC detects the overall thermal change and that change occurs over about a $15^{\circ} \mathrm{C}$ range. The NMR inflection point may show the onset of glass transition. It has been suggested previously by Ablett et al. (1992), based on the results of annealing experiments on sucrose glasses, that the onset of the DSC transition is a more reliable indication of $T_{\mathrm{g}}$. The additional mobile component 3 appeared at almost the same temperature as $T_{\mathrm{c}}$. The $T_{2}$ of this third component $\left(T_{23}\right)$ kept increasing with rising temperature, while that of the second component $\left(T_{22}\right)$ became almost constant over $T_{\text {c }}$.

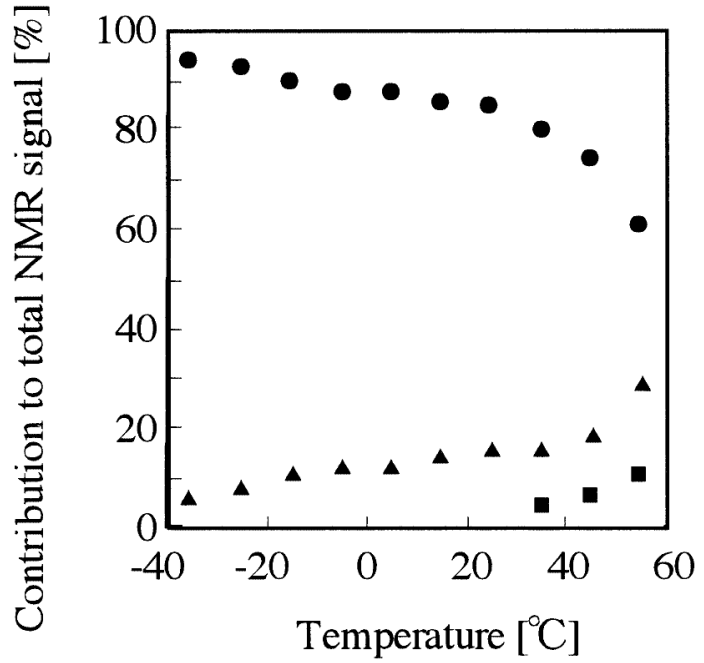

Fig. 16. The relative contribution of amplitudes of the immobile and the mobile components of the FID of glucose syrup with $0.9 \%$ к-carrageenan and $0.14 \% \mathrm{KCl}$ at $8.4 \%$ water content.

๑; component 1, $\mathbf{\Delta}$; component 2, $\mathbf{\square}$; component 3 in Eq. (13).
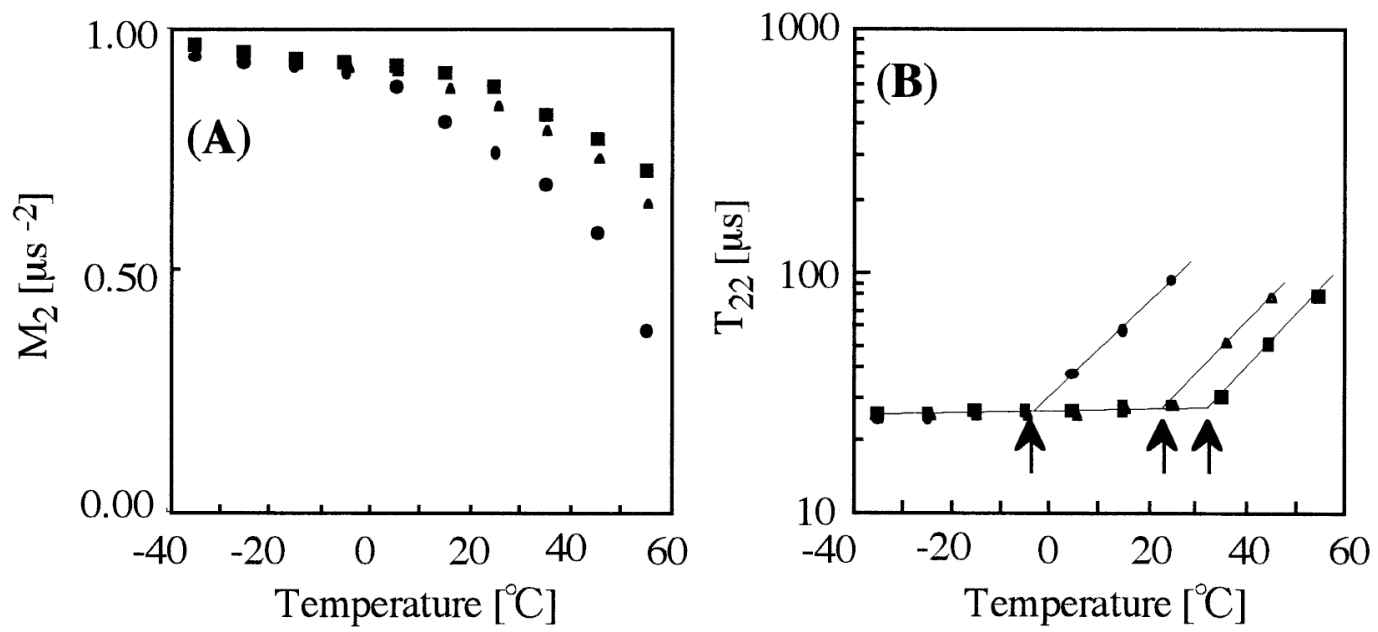

Fig. 15. (A) The second moment of the immobile component $M_{2}$ and (B) the spin-spin relaxation time of the relatively mobile component $T_{22}$ in glucose syrup with $0.9 \%$ к-carrageenan at different water contents.

Water content: $\mathbf{\square} ; 3.5 \%, \mathbf{\Delta} ; 4.7 \%, \bullet ; 8.4 \%$ 
Figure 15 (A) and (B) show the $M_{2}$ and the $T_{22}$ of glucose syrup with $0.9 \% \mathrm{\kappa}$-carrageenan at different water contents, respectively. Transition temperatures of the $M_{2}$ and the $T_{22}$ decreased with increasing water content.

Figure 16 shows the values of the amplitudes of the components of different mobility in glucose syrup with $0.9 \% \mathrm{\kappa}$-carrageenan and $0.14 \% \mathrm{KCl}$ at $8.4 \%$ of water content. The percentage of immobile protons (component 1) decreased with increasing temperature, while that of relatively mobile protons (component 2 ) increased. The additional mobile proton fraction (component 3) appeared at around $35^{\circ} \mathrm{C}$ and increased as temperature rose. The percentage of immobile component was dominant at low temperature, which indicates that most of the protons in the sample are immobile. At $55^{\circ} \mathrm{C}$, the percentages of the immobile (component 1) and the relatively mobile (component 2) proton were $60 \%$ and $30 \%$, respectively. Because the water content of this sample was around $8 \%$ and the content of $\mathrm{\kappa}$-carrageenan was around $1 \%$, most of these immobile and mobile protons must come from glucose syrup. If it is assumed that the protons which are directly attached to the carbons of sugars are less mobile than those in the hydroxyl group, then the percentage of immobile protons is approximately $65 \%$. Therefore, the former would be attributed to the immobile proton and the latter would be to the relatively mobile proton. The percentage of amplitude of the additional mobile protons (component 3 ) was around $10 \%$ at $55^{\circ} \mathrm{C}$ and similar to that of water. Therefore, the additional mobile protons would be attributable to those in water exchangeable with the hydroxyl group.

\subsection{Conclusions on proton NMR analysis of glass transition}

(1) FID was satisfactorily described by a combination of two or three components, Gaussian, exponential, and Gaussian lineshapes.

(2) $M_{2}$ showed one or two transition temperatures, the former being assigned to the glass transition temperature $\left(T_{\mathrm{g}}\right)$, the latter to the critical temperature $\left(T_{\mathrm{c}}\right)$.

(3) $T_{22}$ presented a clear onset of mobility, which was assumed to be the onset of $T_{\mathrm{g}}$.

(4) The additional mobile component appeared at almost the same temperature as $T_{\mathrm{c}}$.

(5) At low temperature, the percentage of the immobile component was dominant, but it decreased as the temperature increased. At high temperature, the protons directly attached to the carbon chains of sugars seemed to be immobile, those in the hydroxyl group to be relatively mobile, and those in water to be more mobile.

\section{Concluding Remarks}

The electrical properties reflect the behavior of electric dipole moments and electrolytes (ions) in the system. The dielectric constant $\varepsilon^{\prime}$ is the sum of the dipole moments over the system and the measured electric current is the total ion flow; therefore, it is often difficult to identify the part of a molecule which the relaxation reflects. However, electrical analysis has an advantage in that a change in the mobility of molecules and/or ions due to the glass transition can be detected even if the sample has a complicated structure, even in the case of a multi-component system like food.

On the other hand, in proton-NMR measurements one can often discern which molecular motion is reflected by parameters such as the spin-spin relaxation time $T_{2}$, if the FID spectra were fitted. However, the results depend on the equation used for fitting, and discussion is often difficult for molecules with a complicated structure.

As mentioned before, information about molecular mobility is important for understanding the stability of glassy foods. Further investigation on these methods is necessary.

\section{References}

Ablett, S., Izzard, M.J. and Lillford, P.J. (1992). Differential scanning calorimetric study of frozen sucrose and glycerol solutions. $J$. Chem. Soc. Faraday Trans., 88, 789-794.

Ablett, A.H., Darke, M.J., Izzard, M.J. and Lillford, P.J. (1993). Studies of the glass transition in malto-oligomers. In "The Glassy State in Foods.” Ed. by J.M.V. Blanshard, P.J. Lillford, Nottingham University Press, Leicestershire, U.K.

Ambrus, J.H., Moynihan. C.T. and Macedo, P.B. (1972). Conductivity relaxation in a concentrated aqueous electrolyte solution. J. Phys. Chem., 76, 3287-3295.

Angell, C.A. (1966). Free volume-entropy interpretation of the electrical conductance of aqueous electrolyte solutions in the concentration range 2-20 N. J. Phys. Chem., 70, 3988-3997.

Angell, C.A. (1990). Dynamic processes in ionic glasses. Chem. Rev., 90, 523-542.

Bannister, D.J., Davies, G.R., Ward, I.M. and McIntyre, J.E. (1984). Ionic conductivities for poly(ethylene oxide) complexes with lithium salts of monobasic and dibasic acids and blends of poly(ethylene oxide) with lithium salts of anionic polymers. Polymer, 25, 1291-1296.

Binks, A.E. and Sharples, A. (1968). Electrical conduction in olefin oxide polymers. J. Polym. Sci. A-2, 6, 407-420.

Borchard, W., Bremer, W. and Keese, A. (1980). The state diagram of the water-gelatin system. Colloid Polym. Sci., 258, 516-526.

Boyd, R.H. (1985). Relaxation processes in crystalline polymers: experimental behaviour-a review. Polymer, 26, 323-346.

Buitink, J., van den Dries, I.J., Hoekstra, F.A., Alberda, M. and Hemminga, M.A. (2000). High critical temperature above $T_{\mathrm{g}}$ may contribute to the stability of biological systems. Biophys. J., 79, 11191128.

Cole, R.H. (1991). Charge motions and dynamics of relaxation. $J$. Non-Cryst Solids, 131-133, 1125-1130.

Cole, R.H. and Tombari E.T. (1991). Analysis of electric relaxation in sodium trisilicate and lithium fluoroborate glasses from 102 to 109 $\mathrm{Hz}$ and 25 to $300^{\circ}$ C. J. Non-Cryst. Solids, 131-133, 969-972.

Dorfmüller T. and Williams G. Ed. (1987). Molecular Dynamics and Relaxation Phenomena in Glasses. Berlin, Springer-Verlag.

Havriliak, S. and Negami, S. (1966). A complex plane analysis of adispersions in some polymer systems. J. Polym. Sci. Part C, 14, 99117.

Higgins, T.J., Macedo, P.B. and Volterra, V. (1972). Mechanical and ionic relaxation in $\mathrm{Na}_{2} \mathrm{O} \cdot 3 \mathrm{SiO}_{2}$ glass. J. Am. Ceram. Soc., 55, 488491.

Hills, B.P. and Pardoe, K. (1995). Proton and deuterium NMR studies of the glass transition in a $10 \%$ water-maltose solution. J. Mol. Liq., 63, 229-237.

Ikeda, S., Kumagai, H. and Nakamura, K. (1997a). Dielectric analysis of food polysaccharides in aqueous solution. Carbohydr. Res., 301, 51-59.

Ikeda, S., Kumagai, H. and Nakamura, K. (1997b). Dielectric analysis of interaction between polyelectrolytes and metal ions within food gels. Food Hydrocolloids, 11, 303-310.

Ikeda, S. and Kumagai, H. (1997). Scaling behavior of physical properties of food polysaccharide solutions: Dielectric properties and viscosity of sodium alginate aqueous solutions. J. Agric. Food Chem., 45, 3452-3458.

Ikeda, S. and Kumagai, H. (1998). Dielectric analysis of sol-gel transition of $\kappa$-carrageenan with scaling concept. J. Agric. Food Chem., 46, 3687-3693.

Iwamoto, S. and Kumagai, H. (1998). Analysis of dielectric relaxation 
of a gelatin solution. Biosci. Biotechnol. Biochem., 62, 1381-1387.

Iwamoto, S. Kumagai, H., Hayashi Y., and Miyawaki O. (1999). Conductance and relaxations of gelatin films in the glassy and rubbery states. Int. J. Biol. Macromolecules, 26, 345-351.

Jain, S.K. and Johari, G.P. (1990). Conductance and relaxations in the glassy and rubber states of aqueous poly(vinyl pyrrolidone): Acryofixation medium. J. Polym. Sci. Part B Polym. Phys., 28, 763-773.

Johari, G.P. (1982). Effect of annealing on the secondary relaxations in glasses. J. Chem. Phys., 77, 4619-4626.

Kalichevsky, M.T., Jaroszkiewicz, E.M., Ablett, S., Blanshard, J.M.V., and Lillford, P.J. (1992). The glass transition of amylopectin measured by DSC, DMTA and NMR. Carbohydr. Polym., 18, 77-88.

Kumagai, H., Sugiyama, T. and Iwamoto, S. (2000). The effect of water content on dielectric relaxation of gelatin in a glassy state. $J$. Agric. Food Chem., 48, 2260-2265.

Kumagai, H., MacNaughtan, W., Farhat, I.A. and Mitchell, J.R. (2002). The influence of carrageen on molecular mobility in low moisture amorphous sugars. Carbohydr. Polym., 48, 341-349.

Levine, H. and Slade, L. (1988). Water as a plasticizer: physico-chemical aspects of low-moisture polymeric systems. In "Water Science Reviews. 3" ed. by F. Franks, Cambridge University Press, New York, 79-185.

Levine, H. and Slade, L. (1993). The glassy state in applications for the food industry, with an emphasis on cookie and cracker production. In "The Glassy State in Foods." ed. by Blanshard, J.M.V., Lillford, P.J., Nottingham University Press, Leicestershire, U.K.

Macedo, P.B., Moynihan, C.T. and Bose, R. (1972). The role of ionic diffusion in polarisation in vitreous ionic conductors. Phys. Chem. Glasses, 13, 171-179.

Marshall, A.S. and Petrie, S,E.B. (1980). Thermal transitions in gelatin and aqueous gelatin solutions. J. Photogr. Sci., 28, 128-134.

Maxwell, J.C. (1873). A treatise on electricity and magnetism. London, Clarendon Press.

McBrierty, V.J. and Packer, K.J. (1995). Nuclear magnetic resonance in solid polymers, Cambridge University Press, Cambridge, UK.

McCrum, N.G., Read, B.E. and Williams, G. (1967). Anelastic and dielectric effects in polymeric solids, John Wiley and Sons, Ltd., London, U.K.

McLin, M. and Angell, C.A. (1988). Contrasting conductance/viscosity relations in liquid states of vitreous and polymer 'solid' electrolytes. J. Phys. Chem., 92, 2083-2086.

Montes, H. M., Mazeau, K. and Cavaille, J.Y. (1997). Secondary mechanical relaxations in amorphous cellulose. Macromolecules, 30, 6977-6984.

Moynihan, C.T., Boesch, L.P. and Laberge, N.L. (1973). Decay function for the electric field relaxation in vitreous ionic conductors. Phys. Chem. Glasses, 14, 122-125.

Moynihan, C.T. (1994). Analysis of electrical relaxation in glasses and melts with large concentrations of mobile ions. J. Non-Cryst. Solids, 172-174, 1395-1407.
Moynihan, C.T. (1996). Analysis of electrical relaxation in ionically conducting glasses and melts. J. Non-Cryst. Solids, 203, 359-363.

Munro, B, Wang, B. and Greenblatt, M. (1996). Impedance measurements on $\mathrm{LiCl}-\mathrm{Al}_{2} \mathrm{O}_{3}-\mathrm{SiO}_{2}$ xerogels. J. Non-Cryst. Solids, 196, 291296.

Murthy, S.S.N., Sobhanadri, J. and Gangasharan. (1994). The origin of $\beta$ relaxation in the organic glasses. J. Chem. Phys., 100, 4601-4606.

Nishinari, K., Shibuya, N. and Kainuma, K. (1985). Dielectric relaxation in solid dextran and pullulan. Makromol. Chem., 186, 433438.

Noel, T.R., Ring, S.G. and Whittam, M.A. (1992). Dielectric relaxations of small carbohydrate molecules in the liquid and glassy states. J. Phys. Chem., 96, 5662-5667.

Noel, T.R., Ring, S.G. and Whittam, M.A. (1993). Relaxations in supercooled carbohydrate liquids. In "The Glassy State in Foods," ed. by J.M.V. Blanshard, and P.J. Lillford, Nottingham University Press, Leicestershire, U.K.

Noel, T.R., Parker, R. and Ring, G.S. (1996). A comparative study of the dielectric relaxation behavior of glucose, maltose, and their mixtures with water in the liquid and glassy states. Carbohydr. Res., 282, 193-206.

Nowick, A.S. and Lim, B.S. (1994). Analysis of ac conductivity data for $\mathrm{Na}_{2} \mathrm{O} \cdot 3 \mathrm{SiO}_{2}$ glass by stretched exponential and Jonscher powerlaw methods. J. Non-Cryst. Solids, 172-174, 1389-1394.

Orford, P.D., Parker, R., Ring, S.G. and Smith, A.C. (1989). Effect of water as a diluent on the glass-transition behavior of malto-oligosaccharides, amylose and amylopectin. Int. J. Biol. Macromol., 11, 91-96.

Pathmanathan, K. and Johari, G.P. (1994). Relaxation and crystallization of water in a hydrogel. J. Chem. Soc. Faraday Trans., 90, 1143-1148.

Provenzano, V., Boesch, P., Volterra, V., Moynihan, C.T. and Macedo, P.B. (1972). Electrical relaxation in $\mathrm{Na}_{2} \mathrm{O} \cdot 3 \mathrm{SiO}_{2}$ glass. J. Am. Ceram. Soc., 55, 492-496.

Rössler, E., Tauchert, J. and Eiermann, P. (1994). Cooperative reorientations, translational motions, and rotational jumps in viscous liquids. J. Phys. Chem., 98, 8173-8180.

Scandola, M., Ceccorulli, G. and Pizzoli, M. (1991). Molecular motions of polysaccharides in the solids state: dextran, pullulan and amylose. Int. J. Biol. Macromol, 13, 254-260.

Tatsumi, T., Ito, E. and Hayakawa, R. (1992). Study of the dielectric $\beta$-relaxation in poly (ethylene terephthalate) and ethylene isophthalate terephthalate copolyesters. J. Polym. Sci.: Part B: Polymer Phys., 30, 701-706.

Van den Dries, I.J., van Dusschoten, D. and Hemminga M.A. (1998). Mobility in maltose-water glasses studies with ${ }^{1} \mathrm{H}$ NMR. J. Phys. Chem. B, 102, 10483-10489.

Wagner, H. and Richert, R. (1997). Dielectric relaxation of the electric field in poly (vinyl acetate): a time domain study in the range $10^{-3}$ $10^{6}$ s. Polymer, 38, 255. 